\title{
The role of intracellular trafficking of CdSe/ZnS QDs on their consequent toxicity profile
}

\author{
Bella B. Manshian ${ }^{1,2^{*}} \mathbb{D}$, Thomas F. Martens ${ }^{3,4}$, Karsten Kantner ${ }^{5}$, Kevin Braeckmans ${ }^{3,4}$, Stefaan C. De Smedt ${ }^{3}$, \\ Jo Demeester ${ }^{3}$, Gareth J. S. Jenkins², Wolfgang J. Parak ${ }^{5,6}$, Beatriz Pelaz ${ }^{5}$, Shareen H. Doak ${ }^{2}$, Uwe Himmelreich ${ }^{1}$ \\ and Stefaan J. Soenen ${ }^{1}$
}

\begin{abstract}
Background: Nanoparticle interactions with cellular membranes and the kinetics of their transport and localization are important determinants of their functionality and their biological consequences. Understanding these phenomena is fundamental for the translation of such NPs from in vitro to in vivo systems for bioimaging and medical applications. Two CdSe/ZnS quantum dots (QD) with differing surface functionality ( $\mathrm{NH}_{2}$ or $\mathrm{COOH}$ moieties) were used here for investigating the intracellular uptake and transport kinetics of these QDs.

Results: In water, the $\mathrm{COOH}$ - and $\mathrm{NH}_{2}$-QDs were negatively and positively charged, respectively, while in serum-containing medium the $\mathrm{NH}_{2}-\mathrm{QDs}$ were agglomerated, whereas the $\mathrm{COOH}-\mathrm{QDs}$ remained dispersed. Though intracellular levels of $\mathrm{NH}_{2}$ - and $\mathrm{COOH}$-QDs were very similar after $24 \mathrm{~h}$ exposure, $\mathrm{COOH}-\mathrm{QDs}$ appeared to be continuously internalised and transported by endosomes and lysosomes, while $\mathrm{NH}_{2}$-QDs mainly remained in the lysosomes. The results of (intra)cellular QD trafficking were correlated to their toxicity profiles investigating levels of reactive oxygen species (ROS), mitochondrial ROS, autophagy, changes to cellular morphology and alterations in genes involved in cellular stress, toxicity and cytoskeletal integrity. The continuous flux of $\mathrm{COOH}-\mathrm{QDs}$ perhaps explains their higher toxicity compared to the $\mathrm{NH}_{2}-\mathrm{QDs}$, mainly resulting in mitochondrial $\mathrm{ROS}$ and cytoskeletal remodelling which are phenomena that occur early during cellular exposure.
\end{abstract}

Conclusions: Together, these data reveal that although cellular QD levels were similar after $24 \mathrm{~h}$, differences in the nature and extent of their cellular trafficking resulted in differences in consequent gene alterations and toxicological effects.

Keywords: Quantum dot NPs, Intracellular localization, Endosomal uptake, Gene alterations, Nanotoxicity

\section{Background}

The scope of the use of nanomaterials (NMs) not only for technological, but also in biomedical and clinical applications is still increasing, where mainly imaging purposes and more recently therapeutic purposes are being explored to greater depth. This is driven by the high number of unique physical and chemical properties that many

\footnotetext{
*Correspondence: bella.manshian@kuleuven.be

1 Biomedical NMR Unit/MoSAIC, KU Leuven Campus Gasthuisberg, Herestraat 49, 3000 Louvain, Belgium

Full list of author information is available at the end of the article
}

materials possess when downsized to the nanoscale. One such type of NM are quantum dots (QDs), which are small colloidal semiconductor nanoparticles (NPs) that possess remarkable photophysical properties, including high photostability and brightness, along with very narrow and size-tunable emission spectra $[1,2]$. These properties have enabled the real-time tracking of surfacelocated receptors in live cells over longer time periods $[3,4]$, as well as intracellular tracking of single molecules and protein [5-7]. QDs also have potential as probes for in vivo fluorescence imaging [8]. They are being explored as therapeutic agents [9], such as in photodynamic 
therapy where the QDs could be used to eradicate cancer cells [10]. Despite alternative materials, the predominantly used QDs are based on II/VI group semiconductor materials, and thus typically comprise Cd. Given their chemical composition and the presence of highly toxic elements such as $\mathrm{Cd}^{2+}[11,12]$, the use of QDs in live cells, tissues, and clinical applications has remained limited. Despite various strategies being explored to reduce their toxicity (e.g. $\mathrm{Cd}^{2+}$-free QDs, dual polymer-silica coated QDs), their practical use in biomedical applications remains moderate. This is in part due to the absence of sufficient information about the precise mechanisms and kinetics involved in the interaction of QDs with biological entities. Some recent studies have tackled this topic [13-15] yet more research is required to understand the effects of specific physico-chemical differences in NPs on their toxicity profiles [16]. Additionally, one inherent issue with the field of nanosafety research is the near endless number of potential interactions of NPs with biological components, of which only a selected few can be examined in every single study for a selected in vitro or in vivo model [17]. As most studies will focus on key mechanisms, such as the induction of reactive oxygen species (ROS) or gross cell viability studies, more subtle effects are often overlooked and differences between the various in vitro and in vivo models used can drastically alter the outcome of any study $[18,19]$. As such, several key questions regarding the potential toxic effects of QDs remain thus far not fully answered.

In the present work, two different types of QDs (bearing negative and positive surface charge) are being used to examine cyto- and genotoxic effects on cultured human cells. Continuing on the results obtained in a previous work with the same QDs [20], further investigations are performed here to evaluate the kinetics of their cellular uptake, intracellular localization, and the alterations they induce to the cellular homeostasis in an effort to attaining a better understanding of the observed differences in their toxicity profiles. Intracellular cadmium levels are quantified and correlated to changes in cellular homeostasis. One major aim of this study is therefore to link the differences in physicochemical parameters with the kinetics of cellular processing and their toxicity levels. A second aim is to further elucidate upon the mechanisms by which the different QDs exert their toxicity. For this purpose, the effect of the intracellular environment on QD functionality and chemical stability are investigated. Additionally, detailed gene expression studies are performed and activation of important cytoskeletal regulator and stress and toxicity signalling pathways are examined. Finally, all results are combined and analysed together, in order to evaluate whether the differences in physicochemical properties of the QDs are linked to their respective uptake kinetics and levels, and whether their intracellular processing also influences QD behaviour and their mechanism of toxicity.

Therefore, this study is a more comprehensive investigation and exploration of the processes responsible for the differences in the cellular and NP interactions that was previously published using the same QDs [20].

\section{Results \\ Properties of the QDs}

The $\mathrm{COOH}$ - and $\mathrm{NH}_{2}$ - $\mathrm{CdSe} / \mathrm{ZnS}$ QDs were purchased from different vendors but both NPs had the same core and surface coating. The diameter of the inorganic part (i.e. the CdSe core and the $\mathrm{ZnS}$ shell, excluding the organic surface coating) of the QDs was determined as $4.6 \pm 0.5 \mathrm{~nm}$ for the carboxyl, $\mathrm{COOH}-\mathrm{QDs}$ (QD-) and $6.9 \pm 0.9 \mathrm{~nm}$ for the amine, $\mathrm{NH}_{2}$-QDs (QD+) (for details please see Additional file 1: Figure S1). The emission spectra were different for the different QDs where $\mathrm{COOH}-\mathrm{QDs}$ had their first excitation peak at 585 and $664 \mathrm{~nm}$ for the $\mathrm{NH}_{2}$-QDs. At the same QD concentration and at $450 \mathrm{~nm}$ excitation the $\mathrm{COOH}$-QDs were much brighter than the $\mathrm{NH}_{2}$-QDs. In water, the $\mathrm{COOH}$ and $\mathrm{NH}_{2}$-QDs were negatively and positively charged, respectively. In serum-containing medium the $\mathrm{NH}_{2}$-QDs were agglomerated (as indicated by the largely increased hydrodynamic diameter), whereas the COOH-QDs remained dispersed (for more QD characterisation information please see the supporting information, a summary is given in Additional file 1: Table S7).

\section{Cellular uptake by confocal microscopy}

Quantum dots internalisation by HFF-1 cells following 4 and $24 \mathrm{~h}$ exposure was examined by confocal microscopy of tubulin stained cells. QDs were confirmed to be in the cells by $3 \mathrm{D}$ imaging. Both, $\mathrm{NH}_{2}$ - and $\mathrm{COOH}-\mathrm{QDs}$ were readily taken up by the cells, as observed from the images (Fig. 1). However, upon semi-quantification of cellular QD levels, clear differences in fluorescence levels were observed after $4 \mathrm{~h}$, where $\mathrm{COOH}-\mathrm{QDs}$ resulted in higher cellular fluorescence. After $24 \mathrm{~h}$, fluorescence had however dropped significantly, reaching the same level as the $\mathrm{NH}_{2}$-QDs. The $\mathrm{NH}_{2}$-QDs did not show any significant differences between 4 and $24 \mathrm{~h}$ exposure and appeared to rapidly reach maximum intracellular fluorescence levels.

\section{Alterations to $\mathrm{QD}$ properties with varying $\mathrm{pH}$ conditions}

The effects of altering $\mathrm{pH}$ levels on the QD properties were tested here by dissolving the NPs in citrate containing PBS the $\mathrm{pH}$ of which was adjusted to 4.5, 5.5, and 7.4 (please see Additional file 1: Figure S11). Our results showed that the fluorescence of the $\mathrm{COOH}-\mathrm{QDs}$ is indeed quenched after $48 \mathrm{~h}$ at all $\mathrm{pH}$ levels and was 


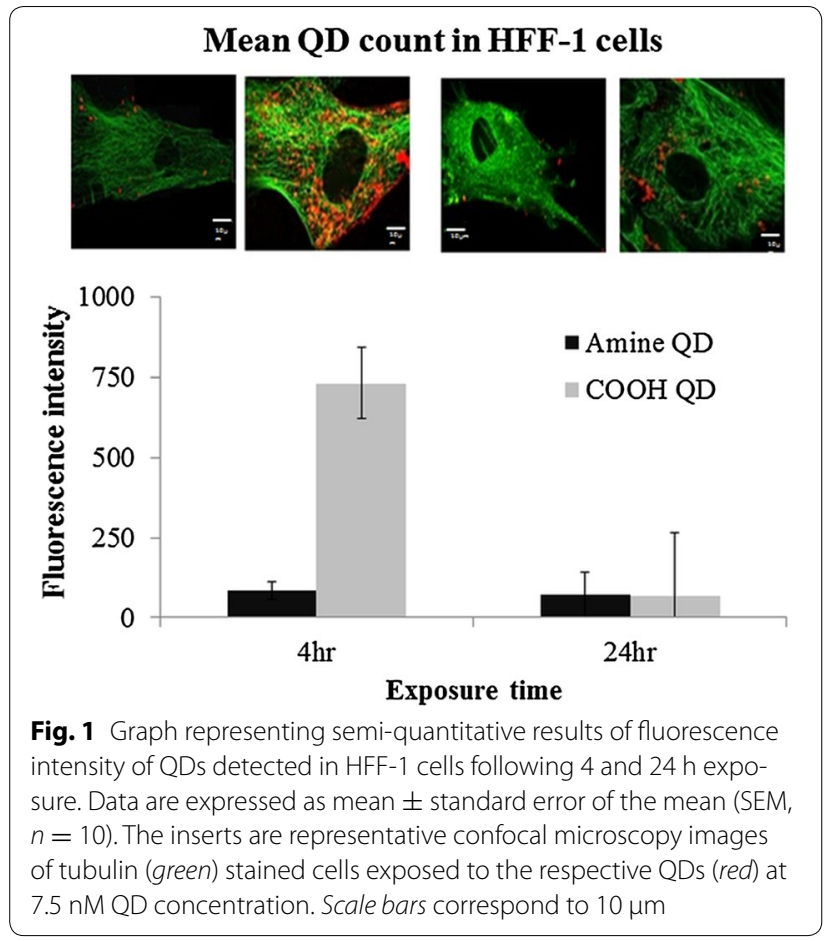

most prominent at the lower $\mathrm{pH}$ levels, but the overall effects were strong in all conditions (Additional file 1: Figure S11A). In contrast, $\mathrm{NH}_{2}-\mathrm{QDs}$ showed no degradation effects of fluorescence following incubation with the three solutions for up to 4 days (Additional file 1: Figure S11B).

\section{Determination of QD properties upon cellular internalization}

To evaluate whether the semiconductor part of the QDs dissolved in the cellular environment, the MeasureIT (Invitrogen Ltd. UK) commercially available kit was used to assess free cadmium ion content in HFF-1 cells treated with $\mathrm{COOH}$ - or $\mathrm{NH}_{2}$-QDs for $24 \mathrm{~h}$. In order to assess the effect of the low endosomal $\mathrm{pH}$ on the QDs, non-proliferating HFF-1 cells were used, as highly proliferative cells would have complicated this analysis by the continuous dilution of both intracellular QDs and intracellular free ions [21]. Data (Additional file 1: Figure S11) revealed significant increases in cellular free $\mathrm{Cd}^{2+}$ levels in $\mathrm{COOH}-$ and $\mathrm{NH}_{2}$-QD treated cells at all the tested time points, starting at day 2, for $\mathrm{COOH}-\mathrm{QDs}$ and starting from day 3 for $\mathrm{NH}_{2}$-QDs.

\section{Evaluation of cellular QD trafficking Confocal microscopy}

Cellular interaction of the two QDs was studied using confocal microscopy based analysis of cells expressing green fluorescent protein (GFP)-tagged Lamp1 (lysosomal marker) or EEA1 (marker for early endosomes). Colocalization between either QD and Lamp1 or EEA1 was determined from the acquired images using the Image J analysis tool. Lysosomes or endosomes were considered as colocalized with the QDs when their respective intensities were higher than the threshold of their individual channels and if their ratio of intensity was more than the ratio setting value [22]. Figure 2 reveals that after $24 \mathrm{~h}$ incubation, there is a clear difference between the two types of QDs, where $\mathrm{NH}_{2}$-QDs result in much higher levels of QDs colocalizing with lysosomes. In contrast, $\mathrm{COOH}-\mathrm{QDs}$ result in much higher levels of QDs colocalizing with early endosomes.

\section{Fluorescence single particle tracking}

In this analysis, the two QDs showed different profiles of uptake and localization in the intracellular environment at the different time points (Fig. 3). $\mathrm{NH}_{2}$-QDs were taken up by the Rab5a-positive early endosomes with endosomal colocalization increasing with time until $1 \mathrm{~h}$ post exposure. They then appeared to be immediately transported into the LAMP1-containing organelles, being mainly lysosomes (Fig. 3a), where the majority of these QDs remained until $6 \mathrm{~h}$ post exposure. The QDs that were not found to be colocalized with Rab5a or LAMP1 (at 120-180 min time points) were likely present in intermediary organelles such as late endosomes [23]. After

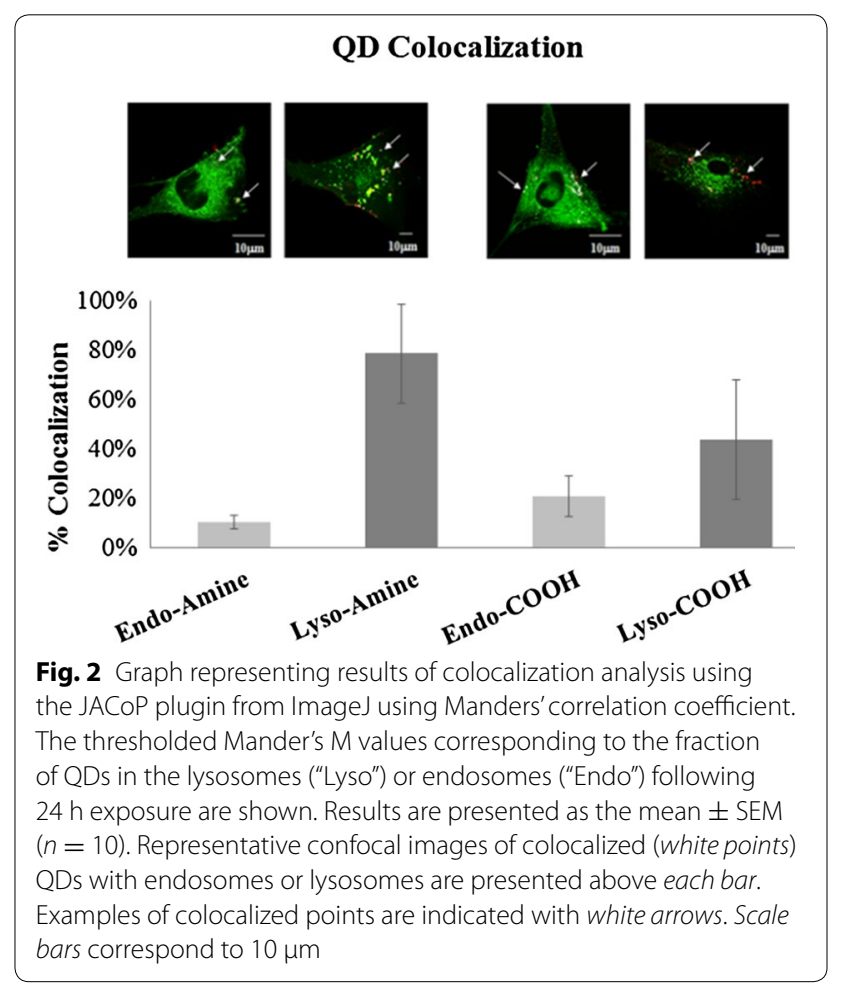



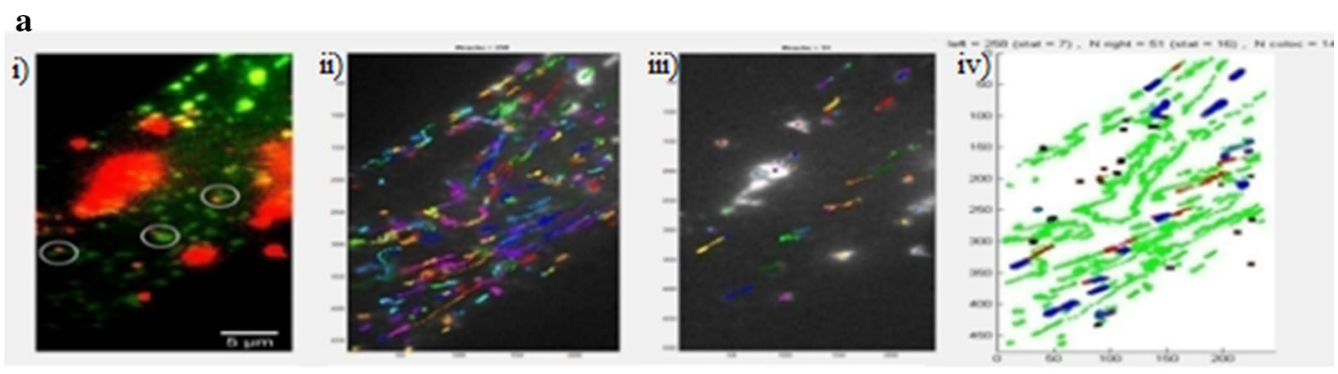

b

Average colocalization Amine-QDs
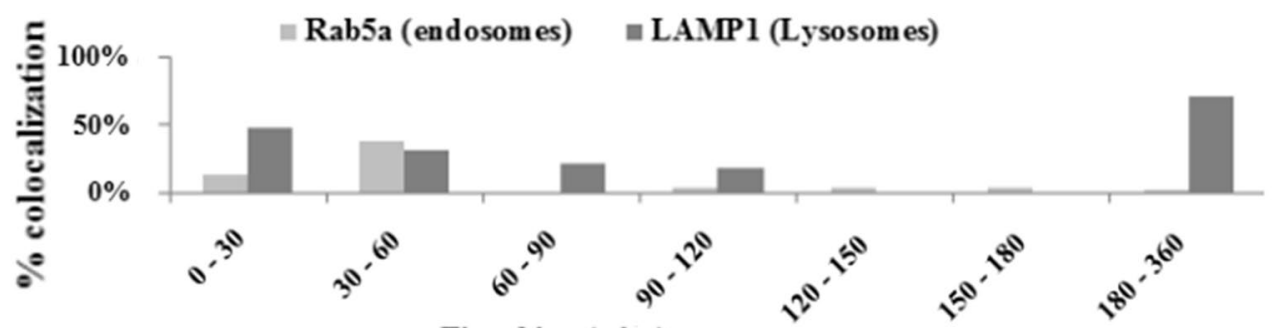

Time bins (mins)

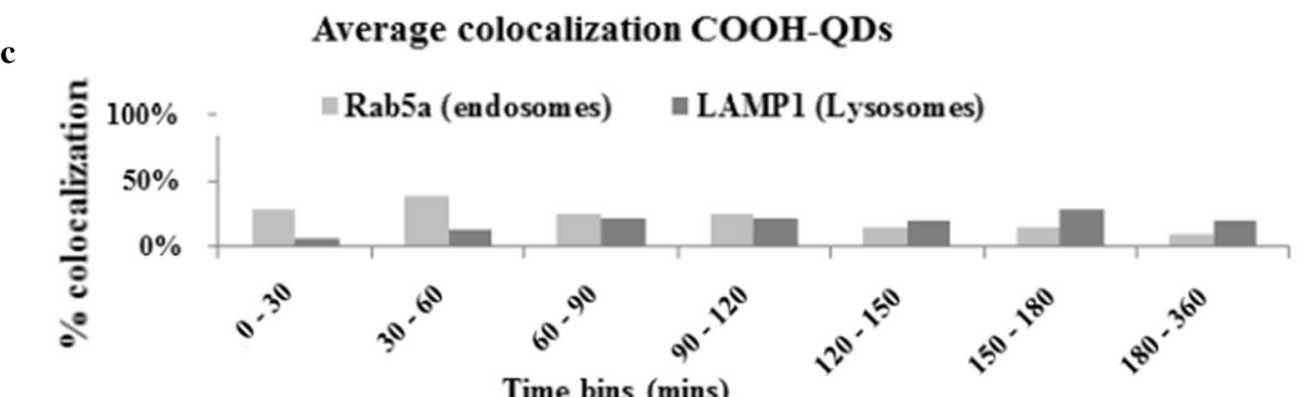

Fig. 3 Plots from the intracellular trafficking profile of QDs in HFF-1 cells using early endosomes-GFP, and lysosomes-GFP. a Images showing an example of the (i) overlay of $\mathrm{NH}_{2}-\mathrm{QD}$ s with the lysosomal marker, (ii) the tracks for the green lysosomal channel, (iii) tracks for the QD channel, and (iv) colocalization of green (lysosomal) and red (QD) tracks. The scale bar corresponds to $5 \mu \mathrm{m}$. b, c Graphs represent trajectory-based dynamic colocalization of fluorescent $\mathrm{NH}_{2}$-QDs with the endosomal marker (Rab5a) and lysosomal marker (LAMP1) that was calculated and plotted as a function of time. Each dot corresponds to 1 min movie recording that was taken in different cells at that specific time point

3-6 h, the majority of the detected QDs were found in the lysosomal compartment. The $\mathrm{COOH}-\mathrm{QDs}$ displayed a completely different profile, where up to $6 \mathrm{~h}$ only a low number of QDs were present in the lysosomal compartment (Fig. 3b).

\section{Exocytosis investigation with ICP-MS}

The results of this analysis (Fig. 4) revealed clear differences in the cellular release of $\mathrm{Cd}^{2+}$ ions by HFF-1 cells, depending on the type of QD. Figure 4a shows that after $4 \mathrm{~h}$ the cell culture media contained sixfold higher amounts of $\mathrm{Cd}^{+2}$ ions following exposure to the $\mathrm{NH}_{2}$-QDs as compared to the COOH-QDs. Higher number of exocytosed $\mathrm{NH}_{2}-\mathrm{QDs}$ as compared to the $\mathrm{COOH}-\mathrm{QDs}$. $\mathrm{COOH}-\mathrm{QDs}$ demonstrated dose and time dependent increase in the level of QDs released into the cell culture media (Fig. 4c). On the other hand, exocytosis of $\mathrm{NH}_{2}$-QDs did not have a time dependent pattern however there was a dose dependency in the $4 \mathrm{~h}$ treatments up to $6 \mathrm{~h}$ post removal of the NPs from the culture media. This pattern has disappeared in the $24 \mathrm{~h}$ experiments (Fig. 4b).

\section{Evaluation of QD induced cellular stress}

Next, the toxic effects of the QDs were evaluated following 4 and $24 \mathrm{~h}$ exposure, using an already validated highcontent imaging approach [14], where a few parameters were selected at sub-cytotoxic concentrations, which were defined in another work [24]. These were the levels of reactive oxygen species (ROS), mitochondrial ROS, 


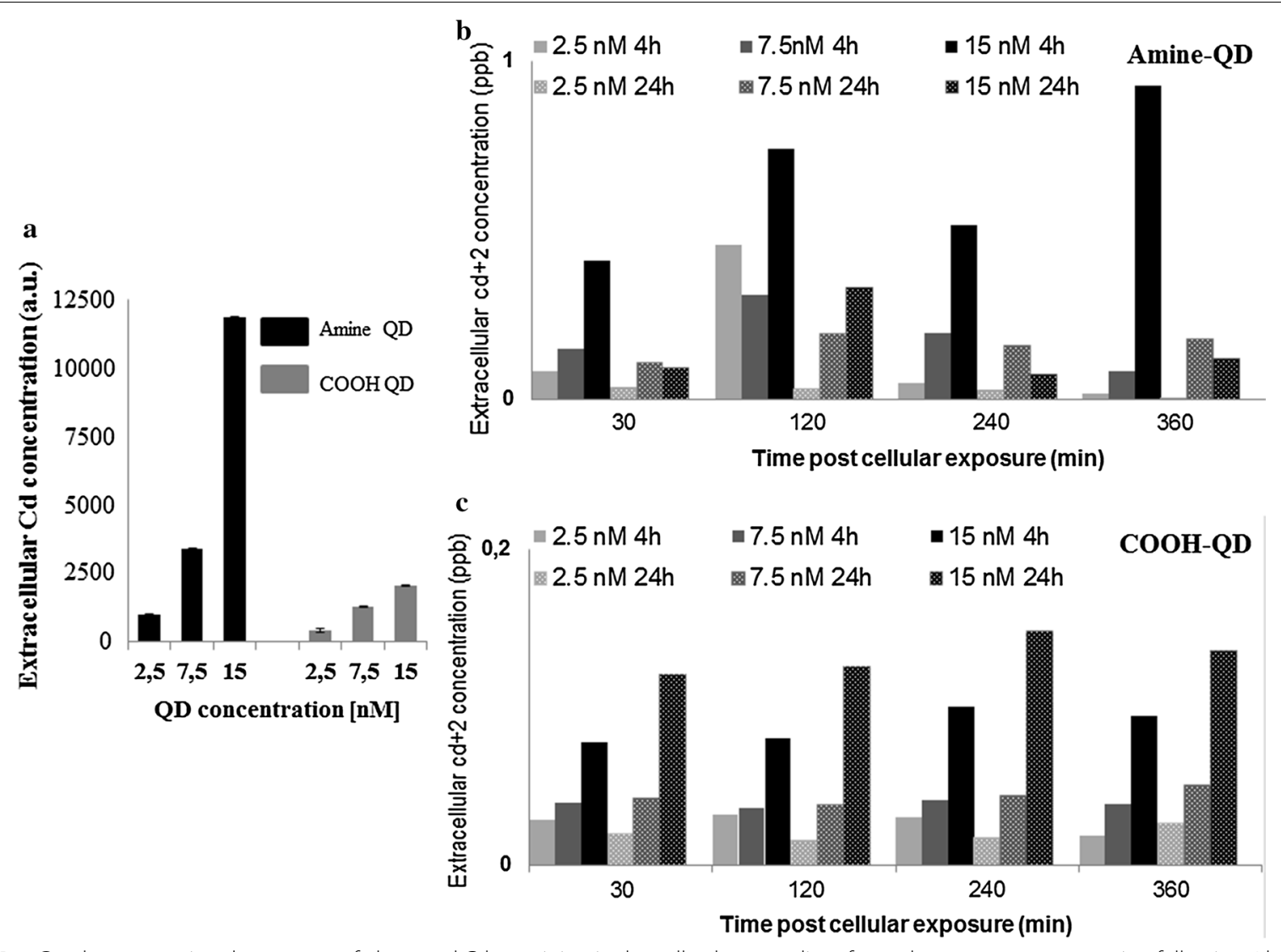

Fig. 4 a Graph representing the amount of elemental $\mathrm{Cd}$ remaining in the cell culture medium for each exposure concentration following $4 \mathrm{~h}$ incubation. b, c Figures showing the number of elemental $\mathrm{Cd}$, relative to the control, detected in the cell culture media at each concentration after $4 \mathrm{~h}$ (solid filled bars) and $24 \mathrm{~h}$ (dotted bars) incubation, which was followed by immediate washing of the cells. Samples were collected and measured with ICP-MS at the different time points. Please note the difference in the $y$-scale between graphs $\mathbf{b}$ and $\mathbf{c}$

induction of autophagy, and alterations to cell morphology. A heat-map is used here to compare toxicity profiles between both types of QDs. For this analysis, the control values were all normalised to $100 \%$. The data show no major effect of the $\mathrm{NH}_{2}$-QDs at any of the parameters tested (Fig. 5, for more detailed results and images see Additional file 1: Figures S12-14). The COOH-QDs however resulted in induction of mitochondrial ROS (Additional file 1: Figure S14) and reduction in cell area after $24 \mathrm{~h}$ exposure (Additional file 1: Figure S13). Neither of the two QD types resulted in a significant effect on cellular autophagy. Neither of the QDs tested here resulted in significant induction of ROS. However, one should keep in mind that there are different types of ROS that can be generated by various processes in different cellular compartments. Here, the mitochondrial-specific probe did indicate induction of mitochondrial ROS, even at the lowest concentration of COOH-QDs. Interestingly, increasing the QD concentration did not correlate with higher levels of mitochondrial ROS, as under the conditions used, a near-constant high level of mitochondrial
ROS was observed, when cells were exposed to the COOH-QDs.

\section{Gene expression studies}

In the arrays investigating genes involved in cellular stress and toxicity different sets of genes were found to be up- or down-regulated following $24 \mathrm{~h}$ exposure to $\mathrm{NH}_{2}$ - or $\mathrm{COOH}$-QDs. $\mathrm{NH}_{2}$-QD exposure resulted in an increase in CCL2, IL1A, IL1B, IL6, IL8, and TNF $\alpha$ genes (Fig. 6a). In contrast, exposure to the higher concentrations (7.5 and $15 \mathrm{nM}$ ) of $\mathrm{COOH}-\mathrm{QDs}$ resulted in the downregulation of several genes mainly involved in the hypoxic processes (Fig. 6b). The most significant of these genes included CFTR, AQP4, and ADM, all of which demonstrated no notable changes from exposure to the $\mathrm{NH}_{2}$-QDs. Significant changes were defined as at least twofold changes as compared to untreated control levels. Another important difference between the two QDs was the significant downregulation of VEGFA recorded with the $\mathrm{COOH}$-QDs which was absent from exposure to the $\mathrm{NH}_{2}$-QDs. On the other hand, like its counterpart, 


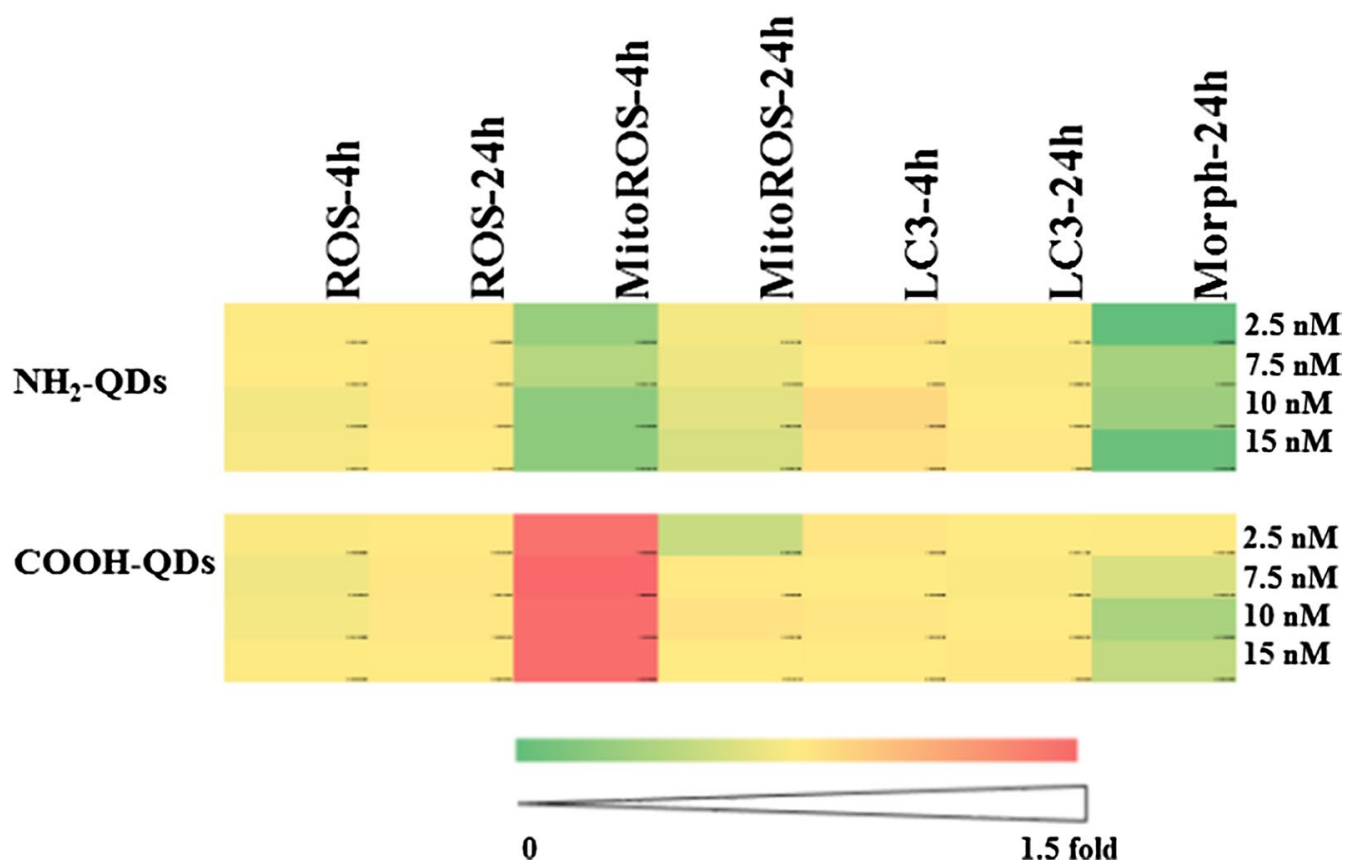

Fig. 5 A heat map of the level of toxicity detected with the different toxicity screening assays upon exposure of the cells to the $\mathrm{NH}_{2}-\mathrm{QDs}$ or $\mathrm{COOH}$ QDs at 2.5, 7.5, 10, and $15 \mathrm{nM}$ concentrations

$\mathrm{COOH}-\mathrm{QD}$ resulted in the upregulation of TNF gene up to $7.5 \mathrm{nM}$ concentration.

The results of the PCR arrays exploring changes to cytoskeletal regulators showed that exposure of the HFF-1 cells to $\mathrm{NH}_{2}$-QDs caused an increase in CCNA1, CDK5R1, IQGAP2, MYLK2, and WAS genes at all tested concentrations. However, the effects were more significant at the two highest concentrations tested (7.5 and $15 \mathrm{nM}$ ) (Fig. 6c).

For COOH-QDs, a set of eleven genes were found to be significantly affected, two of which; MYLK2 and WAS, were also found to be upregulated from exposure to the $\mathrm{NH}_{2}$-QDs (Fig. 6d). For the cells exposed to $\mathrm{COOH}$-QDs, these genes were significantly affected along with others, such as ARAP1, CDC42BPA, and CDC42EP2, which were all significantly downregulated at all the tested concentrations.

\section{Discussion}

\section{Cellular uptake}

Though characterisation studies demonstrated a clear difference in fluorescence intensity between the $\mathrm{NH}_{2}$ and $\mathrm{COOH}-\mathrm{QDs}$, with the latter being much brighter, yet the comparison here is not simply the difference in the uptake level between the two QDs. For the interpretation of the results of confocal microscopy shown in Fig. 1 two different effects need to be discussed. First, a possible difference in cellular internalization of these QDs, as previously demonstrated [20], where negatively charged well dispersed $\mathrm{COOH}-\mathrm{QDs}$ were shown to be more readily taken up in different cell types compared to the positively charged agglomerated $\mathrm{NH}_{2}$-QDs. This however would be in contrast to another study, where positively charged $\mathrm{ZnO}$ NPs, prone to agglomeration, were found to be internalized to a higher extent than negatively charged, well dispersed, polymer-coated ZnO NPs [25]. Second, the possibility that the fluorescence properties of the QDs may have changed, leading to changes in intracellular signal not due to changes in QD concentration, but due to fluorescence loss of the QDs upon being localized in acidic endosomes/lysosomes. According to Additional file 1: Figure S11 this effect is stronger for the $\mathrm{COOH}-\mathrm{QDs}$ than for the $\mathrm{NH}_{2}$-QDs, which would explain the loss of intracellular fluorescence over time of cells incubated with $\mathrm{COOH}-\mathrm{QDs}$. Fluorescence loss in acidic $\mathrm{pH}$ itself may be caused by different mechanisms. Low $\mathrm{pH}$ can cause the generation of trap states by partial loss of the ligands shell, which quenches fluorescence. The latter was tested and described in the next paragraph. Third, some of the QDs may have been exocytosed after being endocytosed [26], which also would lead to a decline in the intracellular fluorescence detected over time.

\section{pH effect on QD stability}

Generally, cellular internalization of NPs occurs through endocytic processes [27], during which NP stability may 


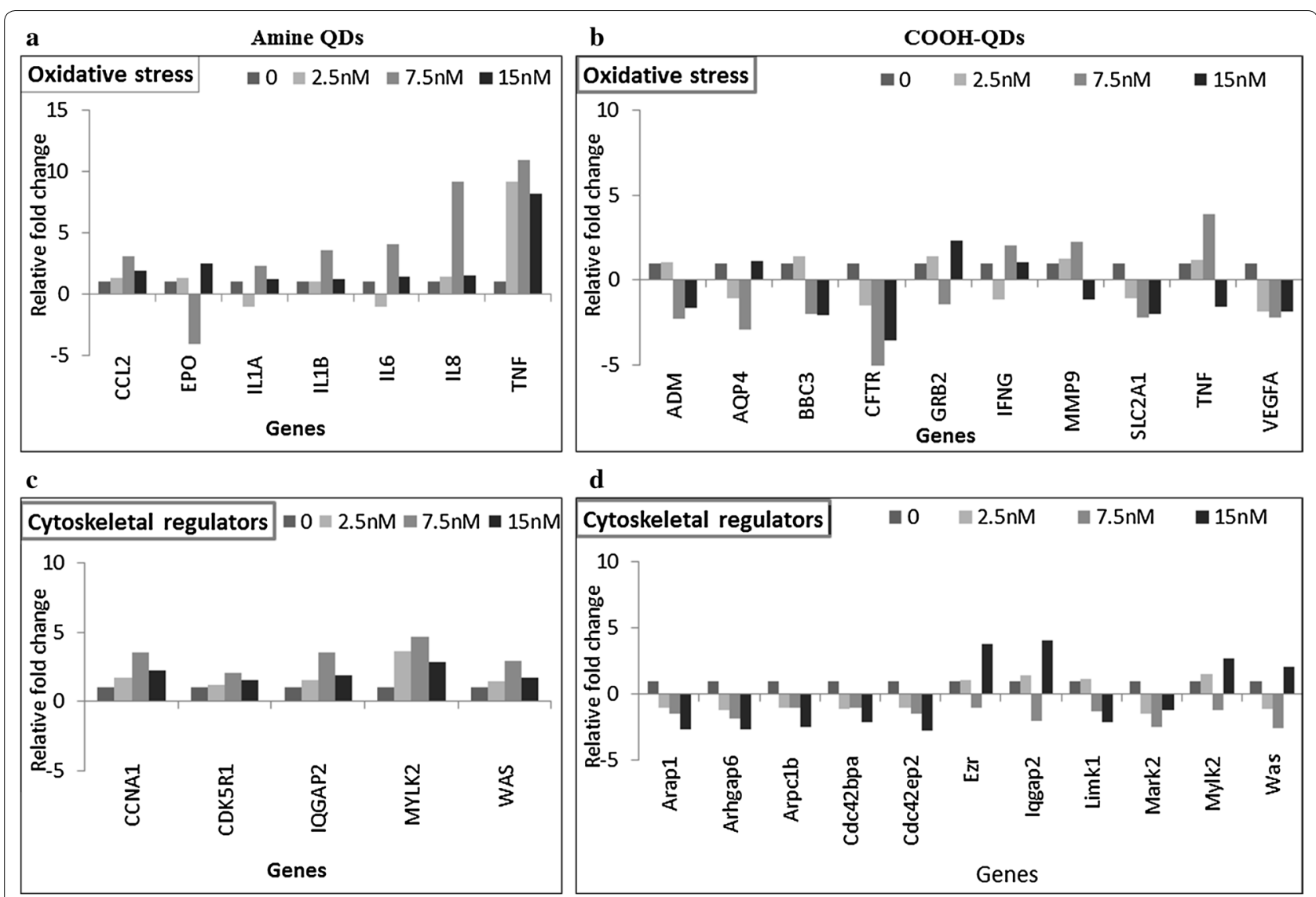

Fig. 6 Graphs showing relative gene expression changes in HFF-1 cells exposed to either $\mathrm{COOH}$ - or $\mathrm{NH}_{2}$-QDs at 0, 2.5, 7.5 or 15 nM concentrations for $24 \mathrm{~h}$. Concentrations were selected where no significant toxicity were detected, along with the negative control. All genes tested are genes involved in the human oxidative stress pathway $(\mathbf{a}, \mathbf{b})$ and the human cytoskeletal regulator gene pathway $(\mathbf{c}, \mathbf{d})$. Only those genes are shown in which for at least one of the tested concentrations a more than twofold change was detected. Data are expressed as the fold-change in mean gene expression values, normalized to the values obtained in untreated control cells

be affected due to changes in the surrounding $\mathrm{pH}$ conditions ranging from $\mathrm{pH} 7.4$ representing the extracellular environment, $\mathrm{pH}$ 5-6 for late and early endosomes, consecutively to the more acidic $\mathrm{pH} 4.5$ of the lysosomal milieu [28]. It has been shown that various NPs, including QDs, are sensitive to the acidic degrading environment of the lysosomes, resulting in a gradual dissolution of the NPs and release of metal ions, which in this case, would be amongst others, highly toxic $\mathrm{Cd}^{2+}$ ions [29]. Therefore, the effect of changing $\mathrm{pH}$ levels on NP stability were tested. The results of this test showed no degradation effects for the $\mathrm{NH}_{2}$-QDs up to 4 days in all three solutions while the $\mathrm{COOH}-\mathrm{QDs}$ were found quenched starting from day 2. It is not clear if this observation is due to the high chemical stability of the $\mathrm{NH}_{2}$-QDs. One possibility is that these QDs formed large aggregates (as seen in the characterisation results in Additional file 1: Figure S8), which could have sedimented to the bottom of the wells, resulting in an absence of significant signal alteration. Concerning the photophysical properties of the two different types of QDs, within the first day of incubation, there was a significant loss in fluorescence of the (initially bright) COOH-QDs (Additional file 1: Figure S11A) but not for the (already initially weakly fluorescent) $\mathrm{NH}_{2}$-QDs (Additional file 1: Figure S11B). The loss in intracellular QD fluorescence from 4 to $24 \mathrm{~h}$ after exposure for the $\mathrm{COOH}-\mathrm{QDs}$ thus could be explained by a possible fluorescence quenching. Partial loss of the ligand shell may have caused the reduction in the fluorescence of the COOH-QDs. However, the $\mathrm{NH}_{2}$-QDs were already initially agglomerated, further loss of ligands is thus less likely and thus the initially already weak fluorescence does not decrease further upon incubation.

Alternatively, low $\mathrm{pH}$ may lead to corrosion of the QDs, i.e. in their dissolution, leading to the release of free $\mathrm{Cd}^{2+}$ ions. In order to investigate the last point, intracellular levels of free $\mathrm{Cd}^{2+}$ ions (i.e. $\mathrm{Cd}^{2+}$ ions released from 
internalized QDs) were detected (Additional file 1: Figure S11C), as explained in the next section.

\section{Changes to QD properties following intracellular uptake}

In the intracellular environment the two QDs appear to have undergone some degradation as evidenced with the free $\mathrm{Cd}^{2+}$ ions detected. Both QDs were significantly degraded in the cell starting at day 2 for the $\mathrm{COOH}-\mathrm{QDs}$ and day 3 for the $\mathrm{NH}_{2}$-QDs. These data are in line with earlier studies on QDs, where degradation of the QDs typically displays a lag time of one to several days, after which there is a gradual increase in cellular $\mathrm{Cd}^{2+}$ levels $[21,30]$. Slower release of $\mathrm{Cd}^{2+}$ from the $\mathrm{NH}_{2}$-QDs may be explained by the fact that they are agglomerated, thus their surface is less accessible. In addition, there is indication that the $\mathrm{ZnS}$ shell around the CdSe core is thicker for the $\mathrm{NH}_{2}$-QDs than for COOH-QDs (Additional file 1: Table S1), which also may account for the slower release of Cd.

The absolute amount of released $\mathrm{Cd}^{2+}$ ions correlates to the number of internalized QDs. However, due to loss in QD fluorescence upon potential partial loss of the ligand shell the data shown in Fig. 1 do not allow us to make a statement about the absolute amount of QDs that has been incorporated by cells. Additional file 1: Figure $\mathrm{S} 11 \mathrm{C}$ shows clear release of intracellular $\mathrm{Cd}^{2+}$ from internalized QDs. Cadmium is a heavy metal that has been shown to be highly toxic in mammalian cells [31]. Free cadmium ions have also been correlated with toxicity detected in cells exposed to cadmium based QDs [32]. However, $\mathrm{Cd}^{2+}$-mediated toxicity would depend on the balance between cell cycle kinetics and degradation kinetics (i.e. the release of $\mathrm{Cd}^{2+}$ ), where toxicity will only occur when the cellular $\mathrm{Cd}^{2+}$ concentration exceeds a certain toxic threshold, which may not be the case for highly proliferating cells (i.e. in the limiting case, if cell division were faster than release of $\mathrm{Cd}^{2+}$ from internalized QDs) then no $\mathrm{Cd}^{2+}$-mediated effects would occur). More subtle, sub-cytotoxic effects will be more easily detected in non-proliferating cells, as they should occur at lower $\mathrm{Cd}^{2+}$ levels. This assumption is supported by a previous publication [20], where significant chromosomal damage was detected in HFF-1 cells exposed to 7.5 nM QD concentration of either the $\mathrm{NH}_{2}$ - or $\mathrm{COOH}$ QDs, conditions under which no acute cytotoxicity was observed.

\section{Intracellular trafficking of the QDs: confocal microscopy, fSPT, and ICP-MS}

In order to gain insight into the kinetics of the uptake of these QDs into HFF-1 cells and to better understand differences in their cellular interaction and consequent effects on cellular homeostasis, we performed confocal microscopy based analysis of cells expressing Lamp1lysosomal marker and EEA1-early endosomal marker. The positively charged $\mathrm{NH}_{2}$-QDs were mainly localized in lysosomal compartments while the $\mathrm{COOH}$-QDs were mostly found to reside in the early endosomes. These results are in good agreement with another study, in which positively charged $\mathrm{FeO}_{x}$ NPs with moderate colloidal stability localized only with lysosome, whereas negatively charged $\mathrm{FeO}_{x}$ NPs with good colloidal stability first were found in endosomes and the later also in lysosomes [33]. These experiments, however, suffer from the high number of endosomes and lysosomes, which requires high lateral resolution in imaging to delineate all the different cellular organelles. Additionally, all these organelles are dynamic and are in constant movement, where in case of not sufficient lateral resolution some colocalization observed might be accidental due to the close proximity of one passing QD (agglomerate) and cellular organelles. Therefore, in order to overcome these limitations these tests were followed with more precise kinetic studies, which involved live tracking of QDs with a dual colour fluorescence single particle tracking (fSPT) system.

The dynamic, trajectory-based colocalization of the QDs with the stained endosomes or lysosomes was analysed using motion trajectories acquired using the fSPT system via the recorded movies of the identified green and red objects. Algorithms in custom built MatLab software were utilised to perform calculations. The dynamic colocalization coefficient, which detected correlated movement between the two objects, was thus the fraction of trajectories of one fluorescence channel that showed correlated movement with trajectories from the second channel. The fSPT system allows for recording of movies of both, the stained organelles and the QDs under investigation, thereby providing time-dependent, live event information regarding the true colocalization of both components [34]. The results obtained from these experiments were in line with our confocal microscopy results explained above. Results were also in agreement with a study in which (polyethylene-coated) gold $(\mathrm{Au})$ NPs, of high colloidal stability, were passed from small vesicles ( $<150 \mathrm{~nm}$, such as endosomes) to bigger vesicles ( $>1000 \mathrm{~nm}$, such as lysosomes), whereas agglomerated $\mathrm{Au}$ NPs had their peak inside small vesicles at intermediate incubation times $(4 \mathrm{~h})$ [35]. In this cited study both Au NPs were negatively charged.

It has been reported that functionalized NPs are prone to exocytosis [36] which is an important parameter to investigate with NPs that are to be used as imaging contrasts, especially that previous studies on Au NPs have demonstrated differences in intracellular NPs due to exocytosis thus highlighting the importance of duration 
and concentration of NP exposure for their optimal use for cell labelling [37]. In order to investigate this parameter and to better understand the results of the confocal microscopy analysis (Fig. 1) from this work, where depletion in fluorescence was noted between 4 and $24 \mathrm{~h}$ time points following exposure of HFF- 1 cells to the $\mathrm{COOH}$ QDs, ICP-MS was conducted. For this purpose, cells were exposed to the QDs for 4 and $24 \mathrm{~h}$, after which the incubation media were removed. Cells were then extensively washed and given fresh QD-free media, after which samples were collected at $0,30,60,120,240$, and $360 \mathrm{~min}$ time points to evaluate the presence of free $\mathrm{Cd}^{2+}$ ions in the extracellular medium. In the following analysis we are assuming that the detected $\mathrm{Cd}$ in the extracellular medium originates from exocytosed QDs (note that ICP-MS measures the elemental amount of $\mathrm{Cd}$, regardless of whether it originates from Cd-based QDs or Cd ions). Also, it is important to note that this assumption excludes QDs sticking to the extracellular membrane, which might not have been removed by the thorough washing steps [38].

The amount of exocytosed QDs should scale with the amount of QDs that have been incorporated by cells before the washing procedure. The higher the exposure concentration of QDs to cells, the higher, thus, the number of exocytosed QDs should be, which was true in these experiments (Fig. 4a). In case one assumes that positively charged agglomerated QDs are internalized to a higher extent than negatively charged well dispersed QDs [25], then the higher number of exocytosed $\mathrm{NH}_{2}$-QDs as compared to the COOH-QDs could be understood. It is also worthwhile noting the difference in the size of the $\mathrm{COOH}$ - and $\mathrm{NH}_{2}-\mathrm{QDs}$ where the latter is slightly larger where one would assume that some of the additional $\mathrm{Cd}$ detected with these NPs is due to the additional $\mathrm{Cd}$ atoms present. However, the extent of released $\mathrm{Cd}$ ions cannot be justified with only this parameter which makes us assume that there is an effect of NP trafficking also involved in the observed difference. Time dependence of exocytosis of the $\mathrm{NH}_{2}$-QDs at low and short exposure condition $(2.5 \mathrm{nM}, 4 \mathrm{~h})$ follows the trend of average colocalization of these QDs with endosomes (Fig. 4b versus Fig. 3b). As in the colocalization experiments time dependence of exocytosis of $\mathrm{NH}_{2}$-QDs does not follow a linear pattern.

\section{Cytotoxicity studies}

The results of the cytotoxicity studies showed a difference in the toxicity profile of the $\mathrm{NH}_{2}$-QDs compared to the $\mathrm{COOH}-\mathrm{QDs}$ where the latter induced more cytotoxicity especially in the form of mitochondrial ROS. Autophagy has been linked to a great variety of NPs [39, 40], and has been associated with different types of QDs in various studies [41, 42], yet no autophagy was found to be induced in these studies. The lack of a clear induction of autophagy is therefore somewhat surprising, but may be due to the nature of the cell type used in the present study. Generally, nanomaterial-induced autophagy is primarily associated with cancer cell types, where in comparative studies, it has been shown that healthy, noncancerous cell types (such as the ones used in this study) display lower levels of autophagy induction [40, 43]. Similarly, even though ROS has been considered to be a key player in toxicological profile of several types of NPs [44], however, some recent studies have suggested that this view may have been exaggerated, in part due to interactions of the NPs with the most common assays used for ROS detection [45]. In particular for imaging-based experiments, the induction of ROS has not been shown to be clearly predominant with many different types of NPs [46]. Moreover, in some other work we have seen that it is mitochondrial oxidative stress that is associated with the NP induced cellular damage [47].

The lack of any significant effect with the $\mathrm{NH}_{2}$-QDs suggests that the mitochondrial ROS induction might be due to the internalization process itself where uptake with these QDs appeared to be less than the COOH-QDs and much more $\mathrm{NH}_{2}$-QDs were found to be exocytosed by the cells compared to the $\mathrm{COOH}-\mathrm{QDs}$.

\section{Gene alterations following QD exposure}

To support the observations obtained above and to gain more insight into the molecular mechanisms involved in the alterations to the cellular homeostasis and to correlate this to the different trafficking mechanism of the two QDs, the gene expression levels of two key cellular pathways were investigated. The first pathway focuses on genes involved in cellular stress and toxicity, and can be seen as an overview of cellular homeostasis. Different sets of genes were upor down-regulated following $24 \mathrm{~h}$ exposure to $\mathrm{NH}_{2}-$ or $\mathrm{COOH}-\mathrm{QDs}$. Cell exposed to $\mathrm{NH}_{2}$-QD resulted the upregulation of CCL2, IL1A, IL1B, IL6, IL8, and TNF $\alpha$ genes, all of which are involved in the induction of inflammatory responses [48]. Similar effects have been reported following exposure to various NPs. For example, exposure of leukocytes, monocytes, and macrophages isolated from human blood, to polystyrene NPs, resulted in an increase in phagocytosis due to the presence of the NPs [49]. In contrast, exposure to $\mathrm{COOH}-\mathrm{QDs}$ resulted in a decrease in an array of genes mainly involved in cellular hypoxia. This finding is in line with earlier findings, where the involvement of genes linked to hypoxia have been associated with cellular NP toxicity [50]. The induction of high levels of mitochondrial metabolism, as indicated by 
the induction of mitochondrial ROS, may result in an artificial hypoxia-like scenario. Although the level of available oxygen is sufficient for basal cellular metabolism, the persistent higher metabolism results in higher energy demands, which may not always be met by the overproducing mitochondria. This "lack of energy" therefore will be highly similar to the typical scenario of low oxygen consumption, resulting in alterations to the expression levels of genes typically associated with hypoxia. The occurrence of hypoxialike processes is interesting, because hypoxia is a main feature of tumor cells resulting in resistance to cancer therapeutic agents [51]. It has been reported that some of the primary adaptive responses to hypoxia include the expression of genes involved in angiogenesis, such as the vascular endothelial growth factor A (VEGFA) gene and the SLC2A1 gene responsible for the metabolic adaption of cells [52]. Previous reports have suggested that the inhibition of these genes could lead to killing of tumor cells or the suppression of resistance to cancer therapeutic agents [51]. This raises the question of whether such NPs could be used for therapeutic applications. Interestingly, no changes were noted in this array from both QDs for the genes involved in oxidative stress which is consistent with our ROS results presented above.

Next to cellular stress and toxicity responses, we also looked into analysis of the cytoskeletal regulator pathway genes. Array results showed that exposure of cells to $\mathrm{NH}_{2}$-QDs induced an increase in the levels of a few genes that are involved in cell mobility and migration. Some of these genes, such as IQGAP2, which effects cellular morphology by regulating the actin cytoskeleton by interacting with cytoskeletal components, cell adhesion, and cell signaling molecules [53-55]. This gene has been implicated in invasion and metastasis of cancer cells [55]. MYLK2, and WAS genes, which were also significantly upregulated in $\mathrm{NH}_{2}$-QD treatments, are involved in the trafficking of molecules into the cell $[56,57]$. Exposure to the COOH-QDs resulted in an array of upregulated and downregulated genes. The most notable ones were ARAP1, CDC42BPA, and CDC42EP2 which are genes involved in forming cell projections and their downregulation is in line with the high-content imaging studies, where at higher $\mathrm{COOH}$ QD concentrations cells were less spread resulting in a lower cell surface area. The deformation of cellular cytoskeleton networks by various NPs is also in line with various other reports, where, in particular at higher NP concentrations, clear deformations of actin and tubulin cytoskeleton have been observed, which could result in secondary effects like altered cellular mobility and migration capacities [58].

\section{Conclusions}

Most NP studies consider physico-chemical properties and their correlation to either kinetics, or toxicity. The present work reveals the importance of understanding how the cell interacts with NPs from a kinetic and mechanistic point of view and then how to interpret these observations to NP properties in an effort to elucidate the differences observed in toxicity and gene alteration results between different NPs. Upon exposing human fibroblasts to two types of QDs, one with $\mathrm{COOH}$ moieties, which was well dispersed, and the other with $\mathrm{NH}_{2}$ moieties, which was agglomerated, the toxicological profile for these QDs was different. The state of agglomeration turned out to be a very relevant physicochemical parameter describing the difference between both types of QDs. The latter clearly had an effect on the process by which the cells trafficked these NPs thus resulting in different effects on cellular homeostasis. The cellular uptake was studied at different time points, where clear differences were observed. $\mathrm{NH}_{2}$-QDs were taken up by the cells rather quickly, but soon resulted in a steady-state level, after which no additional uptake was observed, and were eventually transferred to the lysosomal compartment (Fig. 3b). COOH-QDs followed a different pathway, where they were internalized at a high rate which persisted over at least $6 \mathrm{~h}$ (Fig. 3c). There was only a minimal transfer of $\mathrm{COOH}-\mathrm{QDs}$ to the lysosomal compartment. Generally, both QDs but more so with the $\mathrm{NH}_{2}$-QDs perinuclear localization of the NPs was noted which could be due to the residence of more acidic lysosomes that are performing degradation process in that region [59]. Although no acute cytotoxicity was observed for either of the two QD types under the conditions used, the differences in cellular internalization however resulted in variations in their stress response profile, where high-content imaging and gene expression studies revealed the induction of mitochondrial ROS, cytoskeletal remodelling, and hypoxia-like cellular responses from exposure to the $\mathrm{COOH}-\mathrm{QDs}$, which could all be linked to higher energy demands. A hypothetical sketch is shown in Fig. 7.

Together, these data reveal that though the two QDs differed in physico-chemical properties they were internalised by the cells to a similar extent. Differences in their uptake kinetics, however, appear to be accountable for the significant changes discovered in their toxicity and gene expression profiles.

\section{Methods \\ Cell culture}

Human foreskin fibroblasts HFF-1 (ATCC Manassas, VA) cells were cultured in Dulbecco's Modified Eagle's Medium (DMEM) in the presence of $15 \%$ foetal bovine 


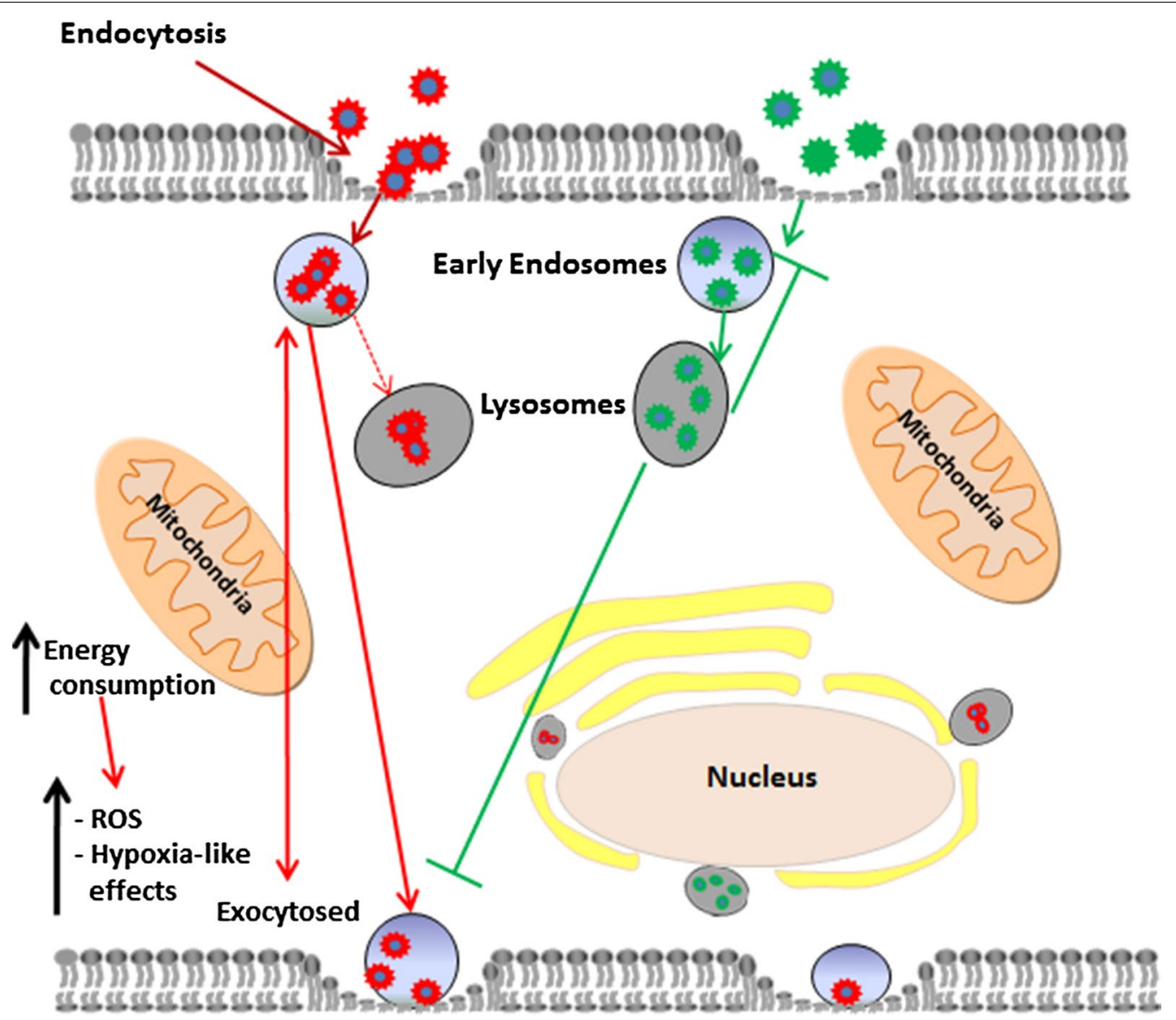

Fig. 7 A figure illustrating the hypothesis that the kinetics of nanoparticle uptake and intracellular processing can vary due to their physico-chemical properties resulting in differences in their toxicity profiles

serum (FBS, Gibco, Life Technologies, Belgium). Cells were incubated at $37{ }^{\circ} \mathrm{C}$ and $5 \% \mathrm{CO}_{2}$ and sub-cultured every third day. All cellular treatments were at $0,2.5,5$, $7.5,10$, and $15 \mathrm{nM}$ concentrations. All experiments were performed in triplicates.

\section{Quantum dot nanoparticles}

Both QDs used in this work were commercial products. CdSe/ZnS core/shell fluorescent NPs with $\mathrm{NH}_{2}$ (Cytodiagnostics, Canada) and $\mathrm{COOH}$ (Invitrogen, UK) functional ligands were used. Details about the structure of the semiconductor part as well as the surface chemistry are not disclosed by the providers. These QDs had emission maxima of $664 \mathrm{~nm}$ (nominally $665 \mathrm{~nm}$ ) and $585 \mathrm{~nm}$ (nominally $590 \mathrm{~nm}$ ). These QDs have been previously thoroughly characterised (please see Additional file 1 for details) [18-20]. QD concentrations for exposure experiments were based on the concentrations of the QDs stocks as given by the suppliers. Cellular exposure stocks were prepared by diluting the QDs in sterile phosphate buffered saline (PBS). All concentration suspensions were vortexed for $30 \mathrm{~s}$ prior to addition to the cell culture. Exposure to QDs were for 4 or $24 \mathrm{~h}$.

\section{QD uptake studies}

Confocal microscopy and ICP-MS analyses were conducted to examine QD uptake into HFF-1 cells following 4 and $24 \mathrm{~h}$ exposure. Details can be found in Additional file 1.

\section{Analysis of photo-stability of the QDs}

The effect of the lowered $\mathrm{pH}$ levels in the intracellular environment on the photo-stability of the QDs was determined by examining the possible effects of altered $\mathrm{pH}$ levels. Experiments were performed as previously described [21]. More details on the methods used can be found in Additional file 1.

\section{Cellular interaction with QDs}

The consequence of cell QD interaction in terms of the generation of cytoplasmic and mitochondrial reactive oxygen species (ROS), the level of the lipidated LC3 protein (marker for autophagy), and cytoskeletal changes 
were investigated using high-content image analysis as detailed previously [14]. A detailed experimental section of these studies can be found in Additional file 1 .

\section{QD tracking studies}

Single particle tracking (SPT) and confocal microscopy based analyses were conducted to track $\mathrm{NH}_{2}$ - or $\mathrm{COOH}$ QDs in the intracellular environment, and to determine their colocalization with endosomes or lysosomes. Full details of the methodology can be found in Additional file 1.

\section{Inductively coupled plasma mass spectrometry (ICP-MS)} Inductively coupled plasma mass spectrometry (ICP-MS) was conducted in order to determine the number of QDs excreted by the cells. For this end, cells were labelled with QDs at 2.5, 7.5, and $15 \mathrm{nM}$ concentrations for 4 and $24 \mathrm{~h}$. Cells were then washed three times with sterile PBS and supplemented with fresh culture media. Samples were collected from the culture supernatant at $0,30,120,240$, and $360 \mathrm{~min}$. The amount of elemental cadmium and selenium in the samples was determined using ICP-MS (see Additional file 1: Section 4 for more details).

\section{Gene expression studies}

Two important human gene expression pathways, the human cytoskeletal regulatory and the cellular stress and toxicity pathways, were investigated using real time polymerase chain reaction (RT-PCR) arrays as described previously [14]. Briefly, $1.5 \times 10^{5}$ cells $/ \mathrm{mL}$ were allowed to settle overnight, followed with incubation with $0,2.5,7.5$, and $15 \mathrm{nM} \mathrm{NH}_{2}$ - or $\mathrm{COOH}-\mathrm{QDs}$ for $24 \mathrm{~h}$ (see Additional file 1: Section 9 for more details).

\section{Statistical analysis}

All data are expressed as the mean \pm standard deviation (SD), unless indicated otherwise. All experiments, except the PCR arrays, were analysed using the One Way Anova statistical method. Significance in the PCR arrays was determined based on twofold change from the control $\Delta \Delta$ Ct value.

\section{Additional file}

Additional file 1. Nanoparticles characterisation, additional materials and methods and data.

\section{Authors' contributions}

The study was planned by BBM and SJS. Particle characterisation, data processing and the writing of part of Additional file 1 was done by WP and BP. ICP-MS was done by KK with guidance from WP. Single particle tracking and MATLAB data analysis were done by BBM and TFM with guidance and input from $K B, S C D, J D$, and $U H$. Toxicity and PCR data analysis and interpretation were done by BBM, SJS, SHD, and GJSJ. The manuscript was written by
BBM with input of all co-authors. All authors read and approved the final manuscript.

\section{Author details}

1 Biomedical NMR Unit/MoSAIC, KU Leuven Campus Gasthuisberg, Herestraat 49, 3000 Louvain, Belgium. ${ }^{2}$ Institute of Life Science, Swansea University Medical School, Singleton Park, Swansea SA2 8PP, UK. ${ }^{3}$ Faculty of Pharmaceutical Sciences, Ghent University, Harelbekestraat 72, 9000 Ghent, Belgium. ${ }^{4}$ Center of Nano- and Biophotonics, Ghent University, Harelbekestraat 72, 9000 Ghent, Belgium. ${ }^{5}$ Philipps University of Marburg, Renthof 7, 35032 Marburg, Germany. ${ }^{6}$ CICBiomagune, San Sebastian, Spain.

\section{Acknowledgements}

We would like to thank Prof. Sebastian Munck and Miss Nicky Corthout from the VIB Centre for Biology of Disease, Belgium for the technical guidance in the use of the IN Cell Analyzer 2000 and IN Cell Developer Toolbox software.

\section{Competing interests}

The authors declare that they have no competing interests.

\section{Availability of data and materials}

All data generated or analyzed during this study are included in the article and its Additional file 1.

\section{Funding}

Part of this work was supported by the FWO Vlaanderen (KAN 1514716N to BBM and KAN $1505417 \mathrm{~N}$ to SJS). Flemish agency for Innovation by Science and Technology (IWT SBO MIRIAD/130065 and NanoCoMIT/140061) and the KU Leuven program financing IMIR (PF 2010/017). Funding of the above listed agencies was applied to design, perform and analyze all cell-based experiments. The UGent consortium NB Photonics supported the single particle tracking experiments performed and the European commission (Grant FutureNanoNeeds to WJP) supported the nanomaterials characterisation part of this work.

\section{Publisher's Note}

Springer Nature remains neutral with regard to jurisdictional claims in published maps and institutional affiliations.

Received: 29 March 2017 Accepted: 6 June 2017

Published online: 15 June 2017

\section{References}

1. Ko EY, Lee Jl, Jeon JW, Lee IH, Shin YH, Han IK. Size tunability and optical properties of CdSe quantum dots for various growth conditions (vol 62, pg 121, 2013). J Korean Phys Soc. 2013;62:1358-1358.

2. Moghaddam MM, Baghbanzadeh M, Sadeghpour A, Glatter O, Kappe CO. Continuous-flow synthesis of CdSe quantum dots: a size-tunable and scalable approach. Chem Eur J. 2013;19:11629-36.

3. Howarth M, Liu W, Puthenveetil S, Zheng Y, Marshall LF, Schmidt MM, Wittrup KD, Bawendi MG, Ting AY. Monovalent, reduced-size quantum dots for imaging receptors on living cells. Nat Methods. 2008;5:397-9.

4. Itano MS, Neumann AK, Liu P, Zhang F, Gratton E, Parak WJ, Thompson $\mathrm{NL}$, Jacobson K. DC-SIGN and influenza hemagglutinin dynamics in plasma membrane microdomains are markedly different. Biophys J. 2011;100:2662-70.

5. Baba K, Nishida K. Single-molecule tracking in living cells using single quantum dot applications. Theranostics. 2012;2:655-67.

6. Biermann B, Sokoll S, Klueva J, Missler M, Wiegert JS, Sibarita JB, Heine M. Imaging of molecular surface dynamics in brain slices using single-particle tracking. Nat Commun. 2014;5:3024.

7. Clarke S, Pinaud F, Beutel O, You C, Piehler J, Dahan M. Covalent monofunctionalization of peptide-coated quantum dots for single-molecule assays. Nano Lett. 2010;10:2147-54.

8. Green M. Semiconductor quantum dots as biological imaging agents. Angew Chem Int Ed. 2004;43:4129-31. 
9. Maity AR, Stepensky D. Efficient subcellular targeting to the cell nucleus of quantum dots densely decorated with a nuclear localization sequence peptide. ACS Appl Mater Interfaces. 2016;8:2001-9.

10. Hsu CY, Chen CW, Yu HP, Lin YF, Lai PS. Bioluminescence resonance energy transfer using luciferase-immobilized quantum dots for selfilluminated photodynamic therapy. Biomaterials. 2013;34:1204-12.

11. Derfus AM, Chan WCW, Bhatia SN. Probing the cytotoxicity of semiconductor quantum dots. Nano Lett. 2004;4:11-8.

12. Kirchner C, Liedl T, Kudera S, Pellegrino T, Munoz Javier A, Gaub HE, Stolzle S, Fertig N, Parak WJ. Cytotoxicity of colloidal CdSe and CdSe/ZnS nanoparticles. Nano Lett. 2005;5:331-8.

13. Yong KT, Law WC, Hu R, Ye L, Liu LW, Swihart MT, Prasad PN. Nanotoxicity assessment of quantum dots: from cellular to primate studies. Chem Soc Rev. 2013;42:1236-50.

14. Manshian BB, Moyano DF, Corthout N, Munck S, Himmelreich U, Rotello VM, Soenen SJ. High-content imaging and gene expression analysis to study cell-nanomaterial interactions: the effect of surface hydrophobicity. Biomaterials. 2014:35:9941-50.

15. Ambrosone A, Roopin M, Pelaz B, Abdelmonem AM, Ackermann LM, Mattera L, Allocca M, Tino A, Klapper M, Parak WJ, et al. Dissecting common and divergent molecular pathways elicited by CdSe/ZnS quantum dots in freshwater and marine sentinel invertebrates. Nanotoxicology. 2017;11:289-303.

16. Del Pino P, Yang F, Pelaz B, Zhang Q, Kantner K, Hartmann R, Martinez de Baroja N, Gallego M, Moller M, Manshian BB, et al. Basic physicochemical properties of polyethylene glycol coated gold nanoparticles that determine their interaction with cells. Angew Chem Int Ed Engl. 2016;55:5483-7.

17. Nel AE, Brinker CJ, Parak WJ, Zink JI, Chan WCW, Pinkerton KE, Xia T, Baer DR, Hersam MC, Weiss PS. Where are we heading in nanotechnology environmental health and safety and materials characterization? ACS Nano. 2015;9:5627-30.

18. Joris F, Manshian BB, Peynshaert K, De Smedt SC, Braeckmans K, Soenen SJ. Assessing nanoparticle toxicity in cell-based assays: influence of cell culture parameters and optimized models for bridging the in vitro-in vivo gap. Chem Soc Rev. 2013;42:8339-59.

19. Tsoi KM, Dai Q, Alman BA, Chan WC. Are quantum dots toxic? Exploring the discrepancy between cell culture and animal studies. Acc Chem Res. 2013;46:662-71.

20. Manshian BB, Soenen SJ, Al-Ali A, Brown A, Hondow N, Wills J, Jenkins GJ, Doak SH. Cell type-dependent changes in CdSe/ZnS quantum dot uptake and toxic endpoints. Toxicol Sci. 2015;144:246-58.

21. Soenen SJ, Demeester J, De Smedt SC, Braeckmans K. The cytotoxic effects of polymer-coated quantum dots and restrictions for live cell applications. Biomaterials. 2012;33:4882-8.

22. Comeau JW, Costantino S, Wiseman PW. A guide to accurate fluorescence microscopy colocalization measurements. Biophys J. 2006;91:4611-22.

23. Zhang LW, Monteiro-Riviere NA. Mechanisms of quantum dot nanoparticle cellular uptake. Toxicol Sci. 2009;110:138-55.

24. Soenen SJ, Rivera-Gil P, Montenegro JM, Parak WJ, De Smedt SC, Braeckmans K. Cellular toxicity of inorganic nanoparticles: common aspects and guidelines for improved nanotoxicity evaluation. Nano Today. 2011;6:446-65.

25. Abdelmonem AM, Pelaz B, Kantner K, Bigall NC, Del Pino P, Parak WJ. Charge and agglomeration dependent in vitro uptake and cytotoxicity of zinc oxide nanoparticles. J Inorg Biochem. 2015;153:334-8.

26. Oh N, Park JH. Surface chemistry of gold nanoparticles mediates their exocytosis in macrophages. ACS Nano. 2014;8:6232-41.

27. Beddoes CM, Case CP, Briscoe WH. Understanding nanoparticle cellular entry: a physicochemical perspective. Adv Colloid Interface Sci. 2015;218C:48-68

28. DiCiccio JE, Steinberg BE. Lysosomal pH and analysis of the counter ion pathways that support acidification. J Gen Physiol. 2011;137:385-90

29. Soenen SJ, Parak WJ, Rejman J, Manshian B. (Intra)cellular stability of inorganic nanoparticles: effects on cytotoxicity, particle functionality, and biomedical applications. Chem Rev. 2015;115:2109-35.

30. Soenen SJ, Montenegro JM, Abdelmonem AM, Manshian BB, Doak SH, Parak WJ, De Smedt SC, Braeckmans K. The effect of nanoparticle degradation on amphiphilic polymer-coated quantum dot toxicity: the importance of particle functionality assessment in toxicology [corrected]. Acta Biomater. 2014;10:732-41.
31. Matovic V, Buha A, Bulat Z, Dukic-Cosic D. Cadmium toxicity revisited: focus on oxidative stress induction and interactions with zinc and magnesium. Arh Hig Rada Toksikol. 2011;62:65-76.

32. Zhang W, Sun X, Chen L, Lin KF, Dong QX, Huang CJ, Fu RB, Zhu J. Toxicological effect of joint cadmium selenium quantum dots and copper ion exposure on zebrafish. Environ Toxicol Chem. 2012;31:2117-23.

33. Schweiger C, Hartmann R, Zhang F, Parak WJ, Kissel TH, Rivera Gil P. Quantification of the internalization patterns of superparamagnetic iron oxide nanoparticles with opposite charge. J Nanobiotechnol. 2012;10:28.

34. Vercauteren D, Deschout H, Remaut K, Engbersen JF, Jones AT, Demeester J, De Smedt SC, Braeckmans K. Dynamic colocalization microscopy to characterize intracellular trafficking of nanomedicines. ACS Nano. 2011;5:7874-84.

35. Brandenberger C, Muhlfeld C, Ali Z, Lenz AG, Schmid O, Parak WJ, Gehr P, Rothen-Rutishauser B. Quantitative evaluation of cellular uptake and trafficking of plain and polyethylene glycol-coated gold nanoparticles. Small. 2010;6:1669-78.

36. Jiang X, Rocker C, Hafner M, Brandholt S, Dorlich RM, Nienhaus GU. Endoand exocytosis of zwitterionic quantum dot nanoparticles by live HeLa cells. ACS Nano. 2010:4:6787-97.

37. Nold P, Hartmann R, Feliu N, Kantner K, Gamal M, Pelaz B, Huhn J, Sun $X$, Jungebluth P, Del Pino P, et al. Optimizing conditions for labeling of mesenchymal stromal cells (MSCs) with gold nanoparticles: a prerequisite for in vivo tracking of MSCs. J Nanobiotechnol. 2017;15:24.

38. Braun GB, Friman T, Pang HB, Pallaoro A, Hurtado de Mendoza T, Willmore AM, Kotamraju VR, Mann AP, She ZG, Sugahara KN, et al. Etchable plasmonic nanoparticle probes to image and quantify cellular internalization. Nat Mater. 2014;13:904-11.

39. Stern ST, Adiseshaiah PP, Crist RM. Autophagy and lysosomal dysfunction as emerging mechanisms of nanomaterial toxicity. Part Fibre Toxicol. 2012;9:20.

40. Peynshaert K, Manshian BB, Joris F, Braeckmans K, De Smedt SC, Demeester J, Soenen SJ. Exploiting intrinsic nanoparticle toxicity: the pros and cons of nanoparticle-induced autophagy in biomedical research. Chem Rev. 2014;114:7581-609.

41. Seleverstov O, Zabirnyk O, Zscharnack M, Bulavina L, Nowicki M, Heinrich $J M$, Yezhelyev M, Emmrich F, O'Regan R, Bader A. Quantum dots for human mesenchymal stem cells labeling. A size-dependent autophagy activation. Nano Lett. 2006;6:2826-32.

42. Li XM, Chen N, Su YY, He Y, Yin M, Wei M, Wang LH, Huang W, Fan CH, Huang Q. Autophagy-sensitized cytotoxicity of quantum dots in PC12 cells. Adv Healthc Mater. 2014;3:354-9.

43. Soenen SJ, Demeester J, De Smedt SC, Braeckmans K. Turning a frown upside down: exploiting nanoparticle toxicity for anticancer therapy. Nano Today. 2013;8:121-5.

44. Nel A, Xia T, Madler L, Li N. Toxic potential of materials at the nanolevel. Science. 2006;311:622-7.

45. Hoet PH, Nemery B, Napierska D. Intracellular oxidative stress caused by nanoparticles: what do we measure with the dichlorofluorescein assay? Nano Today. 2013;8:223-7.

46. George S, Xia TA, Rallo R, Zhao Y, Ji ZX, Lin SJ, Wang X, Zhang HY, France B, Schoenfeld $D$, et al. Use of a high-throughput screening approach coupled with in vivo zebrafish embryo screening to develop hazard ranking for engineered nanomaterials. ACS Nano. 2011;5:1805-17.

47. Siddiqui MA, Alhadlaq HA, Ahmad J, Al-Khedhairy AA, Musarrat J, Ahamed M. Copper oxide nanoparticles induced mitochondria mediated apoptosis in human hepatocarcinoma cells. PLoS ONE. 2013;8:e69534.

48. Wang XM, Hamza M, Wu TX, Dionne RA. Upregulation of IL-6, IL-8 and CCL2 gene expression after acute inflammation: correlation to clinical pain. Pain. 2009;142:275-83.

49. Prietl B, Meindl C, Roblegg E, Pieber TR, Lanzer G, Frohlich E. Nano-sized and micro-sized polystyrene particles affect phagocyte function. Cell Biol Toxicol. 2014;30:1-16.

50. Manshian BB, Pfeiffer C, Pelaz B, Himmelreich U, Parak WJ, Soenen SJ. High-content imaging and gene expression approaches to unravel the effect of surface functionality on cellular interactions of silver nanoparticles. ACS Nano. 2015;9:10431-44.

51. Wilson WR, Hay MP. Targeting hypoxia in cancer therapy. Nat Rev Cancer. 2011;11:393-410.

52. Poon E, Harris AL, Ashcroft M. Targeting the hypoxia-inducible factor (HIF) pathway in cancer. Exp Rev Mol Med. 2009;11:e26. 
53. White CD, Khurana H, Gnatenko DV, Li Z, Odze RD, Sacks DB, Schmidt VA. IQGAP1 and IQGAP2 are reciprocally altered in hepatocellular carcinoma. BMC Gastroenterol. 2010;10:125.

54. Yamashiro S, Abe H, Mabuchi I. IQGAP2 is required for the cadherinmediated cell-to-cell adhesion in Xenopus laevis embryos. Dev Biol. 2007;308:485-93.

55. Jin SH, Akiyama Y, Fukamachi H, Yanagihara K, Akashi T, Yuasa Y. IQGAP2 inactivation through aberrant promoter methylation and promotion of invasion in gastric cancer cells. Int J Cancer. 2008;122:1040-6.

56. Daniele T, Di Tullio G, Santoro M, Turacchio G, De Matteis MA. ARAP1 regulates EGF receptor trafficking and signalling. Traffic. 2008;9:2221-35.
57. Guo FJ, Liu Y, Huang JA, Li YH, Zhou GH, Wang D, Li YL, Wang JJ, Xie PL, Li GC. Identification of Rho GTPase activating protein 6 isoform 1 variant as a new molecular marker in human colorectal tumors. Pathol Oncol Res. 2010;16:319-26.

58. Tay CY, Cai P, Setyawati MI, Fang W, Tan LP, Hong CH, Chen X, Leong DT. Nanoparticles strengthen intracellular tension and retard cellular migration. Nano Lett. 2014;14:83-8.

59. Zaarur N, Meriin AB, Bejarano E, Xu X, Gabai VL, Cuervo AM, Sherman MY. Proteasome failure promotes positioning of lysosomes around the aggresome via local block of microtubule-dependent transport. Mol Cell Biol. 2014;34:1336-48.

\section{Submit your next manuscript to BioMed Central and we will help you at every step:}

- We accept pre-submission inquiries

- Our selector tool helps you to find the most relevant journal

- We provide round the clock customer support

- Convenient online submission

- Thorough peer review

- Inclusion in PubMed and all major indexing services

- Maximum visibility for your research

Submit your manuscript at www.biomedcentral com/submit 